NASA Technical Memorandum 106471

AIAA-94-0716

\title{
An Overview of a Model Rotor Icing Test in the NASA Lewis Icing Research Tunnel
}

Randall K. Britton

Sverdrup Technology, Inc.

Lewis Research Center Group

Brook Park, Ohio

Thomas H. Bond

Lewis Research Center

Cleveland, Ohio

and

Robert J. Flemming

Sikorsky Aircraft Division, UTC

Stratford, Connecticut

Prepared for the

32nd Aerospace Sciences Meeting

sponsored by the American Institute of Aeronautics and Astronautics

Reno, Nevada, January 10-13, 1994 


\title{
An Overview of a Model Rotor Icing Test in the NASA Lewis Icing Research Tunnel
}

\author{
Randall K. Britton \\ Sverdrup Technology, Inc. \\ NASA Lewis Research Center Group \\ Brook Park, Ohio \\ Thomas H. Bond \\ NASA Lewis Research Center \\ Cleveland, Ohio \\ Robert J. Flemming \\ Sikorsky Aircraft Division, UTC \\ Stratford, Connecticut
}

\begin{abstract}
During two entries in late 1989, a heavily instrumented sub-scale model of a helicopter main rotor was tested in the NASA Lewis Research Center (LeRC) Icing Research Tunnel (IRT). The results of this series of tunnel tests have been published previously. After studying the results from the 1989 test and comparing them to predictions, it became clear that certain test conditions still needed investigation. Therefore, a re-entry of the Sikorsky Aircraft Powered Force Model (PFM) in the IRT was instituted in order to expand upon the current rotorcraft sub-scale model experimental database. The major areas of interest included expansion of the test matrix to include a larger number of points in the FAA AC 29-2 icing envelope, inclusion of a number of high power rotor performance points, close examination of warm temperature operations, operation of the model in constant lift mode, and testing for conditions for icing test points in the full scale helicopter database. The expanded database will allow further and more detailed examination and comparison with analytical models. Participants in the test were NASA LeRC, the U.S. Army Vehicle Propulsion Directorate based at LeRC, and Sikorsky Aircraft. The model rotor was exposed to a range of icing conditions (temperature, liquid water content, median droplet diameter) and was operated over ranges of shaft angle, rotor tip speed, advance ratio, and rotor lift. The data taken included blade strain gage and balance data, as well as still photography, video, ice profile tracings, and ice molds. A discussion of the details of the test is given herein. Also, a brief examination of a subset of the data taken is also given.
\end{abstract}

\section{Nomenclature}

$\begin{array}{llll}\mathrm{C}_{\mathrm{L}} & \text { Rotor Lift Coefficient } & \mathrm{V}_{\infty} & \text { Tunnel Velocity }(\mathrm{ft} / \mathrm{sec}) \\ \mathrm{C}_{\mathrm{Q}} & \text { Rotor Torque Coefficient } & \sigma & \text { Rotor Solidity } \\ \mathrm{LWC} & \text { Liquid Water Content }\left(\mathrm{g} / \mathrm{m}^{3}\right) & & \text { Advance Ratio } \\ \mathrm{MVD} & \text { Droplet Diameter }(\mu \mathrm{m}) & \mu & \text { Rotor Tip Speed }(\mathrm{ft} / \mathrm{sec}) \\ \mathrm{T} & \text { Static Air Temperature }\left({ }^{\circ} \mathrm{C}\right) & \Omega \mathrm{R} & \text { Shaft Angle }(\mathrm{deg} .) \\ \mathrm{R} & \text { Rotor Radius }(\mathrm{ft}) & \alpha & \text { Icing Time }(\mathrm{sec}) \\ \mathrm{L} & \text { Main Rotor Lift }(\mathrm{lbs}) & \Delta \tau & \text { Air Density }\left(\mathrm{slugs} / \mathrm{ft} \mathrm{t}^{3}\right) \\ \mathrm{c} & \text { Chord }(\mathrm{ft}) & \rho & \end{array}$




\section{Introduction}

Icing has historically been a problem for aircraft, especially helicopters. Rotor systems are very sensitive to icing because of high accretion rates and vibration associated with asymmetric shedding. Most U.S. helicopters (military and civilian) have restricted or no clearance for operation in forecasted icing conditions. One of the major reasons for this is the prohibitive cost of qualification/certification. Current procedures for certification place emphasis on full scale flight testing in natural icing conditions. Many required test conditions from the icing envelope do not readily occur in nature. Further, the helicopter's short range (relative to its fixed-wing counterparts) essentially forces researchers to sit and wait for the correct weather conditions rather than "chase" icing. This usually results in very long and expensive flight test programs which span several icing seasons. The French Super Puma icing flight test program spanned nine years at a very high cost before certification for flight into icing was obtained. Most U.S. helicopter manufacturers agree that this level of expenditure for certification is not economically feasible for any domestic helicopter program. There is, however, a market for all weather helicopters in the civilian arena. The major roadblock U.S. manufacturers face is the cost of certification. Thus, there is a need to develop validated, less expensive alternatives to icing flight testing. Although flight testing will always be required, validated lower cost alternatives can alleviate complete dependence on it as a means for certification and thereby reduce certification cost.

Because of this need, the NASA Lewis Research Center (LeRC) formed the Helicopter Icing Consortium (HIC) in 1985. This consortium was composed of members from the U.S. helicopter industry, academia, the Army, and NASA. The HIC began an ambitious test program which was designed to demonstrate that a model helicopter could be successfully tested in the NASA LeRC Icing Research Tunnel (IRT) and yield useful data. The test program consisted of a single test of a lightly instrumented OH-58 Tail Rotor Rig in 1988 and two tests of the heavily instrumented
Sikorsky Powered Force Model (PFM) in 1989. These tests were very successful, as documented in References 1,2 , and 3.

Upon completion of the 1989 tests it became clear that there were certain test conditions of interest still missing from the database. Therefore, a re-entry of the PFM in the IRT was instituted in order to expand the database obtained during the previous test program. The major areas of interest were as follows:

1) Expansion of the test matrix to include a larger number of points in the FAA AC 29-2 icing envelope.

2) Inclusion of a number of high power rotor performance points and other rotor icing data not available in the 1989 test.

3) Close examination of warm temperature (near and slightly above freezing) operations.

Operation of the model in constant lift mode to simulate more realistic flight profiles during an icing encounter.

5) Test at conditions corresponding to available full scale helicopter icing database.

This expanded database will allow further and more detailed examination and comparison with analytical models. Participants in the test were NASA LeRC, the U.S. Army Vehicle Propulsion Directorate, and Sikorsky Aircraft. A total of 220 runs were completed throughout the test. Of those, 208 were icing events, and the others were system check-out, tare, balancing, and baseline runs. The program was funded in two parts. The first was set up as a contract between NASA and Sikorsky. The second part of the test program was a cooperative Space Act Agreement between Sikorsky and NASA. There were 71 icing test runs performed during the contract portion of the test and the remaining 137 icing points were tested under the Space Act Agreement. This paper will provide an overview of the test as 
well as a few examples of the data obtained. The data discussed will be from the contract portion of the test.

\section{Test Apparatus Description}

\section{Icing Research Tunnel}

The IRT was designed and built in the early 1940s. The IRT is a closed-loop refrigerated wind tunnel. A 4100-hp fan provides airspeeds up to $134 \mathrm{~m} / \mathrm{s}(300 \mathrm{mph})$ in an empty test section. The 21,000-ton-capacity refrigeration heat exchanger can vary the total temperature from $5^{\circ}$ to $-42^{\circ} \mathrm{C}$ (Figure 1). The spray nozzles provide droplet sizes from 11 to $40 \mu \mathrm{m}$ median volume diameter (MVD) with liquid water contents (LWC) ranging from 0.2 to $3.0 \mathrm{~g} / \mathrm{m}^{3}$ The tunnel is $1.8 \mathrm{~m}(6 \mathrm{ft})$ high and $2.7 \mathrm{~m}$ ( $9 \mathrm{ft}$ ) wide. In 1986 it underwent a major rehabilitation which provided faster and more accurate control of the tunnel conditions. A similar upgrade to the refrigeration plant and its controls was completed in 1991.

For this test, armor plates were attached to the walls of the tunnel test section covering the visual access areas to protect personnel in the control room. Video systems were installed to monitor the test area, local rotor blade positions, and provide blade tracking information. Reference 1 gives a complete description of the setup for the 1989 PFM test which was very similar to the setup for the current test entry.

\section{Model Rotor Test Rig}

The Sikorsky PFM is a general purpose rotor test apparatus that has been installed in a number of wind tunnels and hover facilities, including the Icing Research Tunnel (Figure 2). The model can be configured with a fuselage balance, powered tail rotor, and empennage. However, the installation was simplified for this test to a model main rotor mounted on a six component balance, with UH-60 BLACK HAWK fuselage skins. The main rotor was located in a position $1.02 \mathrm{~m}(3.33 \mathrm{ft})$ above the tunnel floor, $0.1 \mathrm{~m}(0.33 \mathrm{ft})$ above the tunnel centerline. The PFM BLACK HAWK fuselage skins are scaled to $1 / 5.727$ of full scale, as are the standard UH-60 blades used for this test apparatus. However, IRT wall constraints dictated that the scaled blades (2.86 $\mathrm{m}$ or $9.37 \mathrm{ft}$ diameter) be truncated to a diameter of $1.86 \mathrm{~m}(6.09 \mathrm{ft})$ for this test.

The model was driven by two Able 60 HP 3-phase variable frequency induction electric motors, providing a maximum rotor speed of 2286 RPM, for a maximum tip speed of $222 \mathrm{~m} / \mathrm{s}$ (729 ft/s). Model power was provided by a variable frequency motorgenerator set provided by the Aeroflightdynamics Directorate of ATCOM. The motor generator set had a constant rotor speed feedback system that maintained a constant RPM throughout an icing encounter.

Rotor head forces and moments were measured using a six component balance that was gimbal mounted to the model frame. The balance was electrically heated to maintain it at the calibration temperature of $20^{\circ} \mathrm{C}$. Rotor torque was measured using a separate load cell that measured the reaction force between the gearbox (mounted on a bearing) and the gearbox frame.

The four-bladed main rotor was fully articulated and was controlled through a conventional rotorcraft system of rotating pushrods and scissors, a swashplate, three electromechanical actuators, and a stationary scissors. Control inputs were made at a control console that electronically mixed the inputs to move the actuators. Rotor blade motions (flapping, lead-lag, and collective pitch) were measured and could be used by a feedback controller to maintain the rotor at a constant flapping position. The control console also included a rotor lift feedback system which could be used to maintain the rotor at a constant $\mathrm{C}_{\mathrm{L}} / \sigma$ throughout an icing encounter. Rotor shaft angle was set prior to an icing encounter and held constant during each run.

The articulated rotor head, as configured for this test, had coincident flap and lag hinges located at the $8.3 \%$ radial station. There was no pitch-flap coupling. The rotor lead-lag dampers were electrically heated to maintain the fluid at a constant viscosity. The main rotor blades were of composite construction with a 
chord of $10.72 \mathrm{~cm}$ (4.22 in). The blades had the Sikorsky SC2110 airfoil, which is a modern cambered rotorcraft airfoil with a thickness to chord ratio of $10 \%$. The blades had a linear twist of $-11.5^{\circ}$. The rotor blades were painted with blade number and spanwise markings to aid in photo documentation.

\section{Instrumentation}

The test used an instrumentation system that acquired data for both research and safetyof-flight use. Research instrumentation, in addition to the balance measurements and blade motion sensors noted above, included rotor RPM, IRT temperatures and pressures, time varying LWC, pushrod loads, and blade strains. The primary instrumented blade had five flatwise, five edgewise, and three torsion strain gages. The other blades had a root edgewise strain gage to indicate the times of shedding events. Additional safety-of-flight instrumentation included model thermocouples, accelerometers, flow meters, and limit indicators.

\section{Data Acquisition}

The total data collection process included the Sikorsky Aircraft HP 9000 portable data acquisition system, IRT information on velocity, temperature, and liquid water content, conventional and strobe illuminated imaging, photographic and manual records pertaining to the accreted ice, plus a number of other measurement and cataloguing techniques.

The Hewlett Packard 9000 series portable data acquisition system sampled data in the rotor domain reference system at a rate of 16 samples per blade revolution. Simultaneous sample-and-hold amplifiers froze the analog channels before digitizing to maintain a consistent data snapshot. Processing of the data included correction for tunnel blockage, model gimbal motion, shaft torque tare, gravity tares, and induced angle of attack. The data from the first 10 revolutions in each second (total of 160 data samples) were then averaged to create a data record. Processed data records were then transmitted to a personal computer for formatting into EXCEL spreadsheets for analysis and plotting.

The video records provided a viewing history of the ice accretion and shedding. There were three separate video systems: one for safety monitoring, one for blade tracking (which also provided good ice profile shapes near the blade tip), and one that allowed close-up images of the rotor blades. The three systems were strobe driven by a signal off the rotor shaft angle encoder. This gave a "frozen" image of the blade. The close-up data video system for local rotor blade monitoring was installed on a tilt and pan mechanism along with a $35-\mathrm{mm}$ camera that had a $400-\mathrm{mm}$ zoom lens. This video system had the capability of traversing the entire diameter of the main rotor while allowing zoom shots of as small a span as $0.10 \mathrm{~m}(0.3283 \mathrm{ft})$ of the blade leading edge. The $35-\mathrm{mm}$ camera was focused on the same close-up viewing area as the video camera, allowing pictures with greater resolution and clarity to be taken. Both the data video and the $35-\mathrm{mm}$ camera were triggered from the same strobe to provide an accurate replication of the video image for the $35-\mathrm{mm}$ camera.

Liquid water content information (rise time, cloud stabilization, and spray bar lag from spray initiation) was recorded from the Control Room console output. A Johnson-Williams (J-W) LWC meter also measured the LWC within the test section. Spray times, temperatures, and general comments were noted.

Several kinds of post-run information about the accreted ice were gathered. Still pictures with a 35-mm camera were taken of the blade planform, an end profile, and any unusual ice formations. Close-up shots of ice growths were taken to record their minute detail. A heated aluminum block with a cut-out contour of the airfoil shape was used to make a clean slice through the ice formation. A cardboard template was then held against the ice shape and a tracing made. This process also provided ice thickness values along the blade at discrete spanwise and chordwise locations. Visual observations were recorded about the kind of ice, any secondary growth, and frost formation. Molds were taken of two blades on eight test runs including two repeat conditions. While 
this documentation was taking place the data files of the test run were backed up and a copy was downloaded to a micro-computer for post-test processing.

\section{Run Procedure}

The test techniques used in the IRT were based on rotorcraft model operating experience and procedures developed during earlier entries in the wind tunnel1,2,3. At the beginning of a test shift, the model was operated while the IRT temperature was stabilized at the first test condition temperature. At the end of the shift, the tunnel was generally operated (along with the model) to increase the tunnel temperature above freezing and dry out the tunnel.

A typical test run began by bringing the PFM up to speed to exercise the rotor, then shutting the model down to take static balance and gage readings. The model was then brought up to operating speed and the rotor was stabilized. At this time, a dynamic zero (wind off, zero collective) was taken. The rotor speed was then dropped to some nominal level while the tunnel controls were set and the tunnel started up. When the tunnel conditions were stable the model operator returned the rotor to the desired speed and set the rotor conditions. The data engineer then initiated data acquisition and the tunnel operator initiated the spray sequence. At the end of the run the tunnel rpm was brought down to idle (taking approximately two minutes) while the model operator lowered the rotor speed to a fall back position. When the tunnel test section speed was below 10 knots the rotor was stopped. After the run the researchers entered the test section and documented the resulting ice accretion. The assembly was deiced and conditions set for the next run.

The tests for which ice molds were to be taken were the last of the day. Prior to the test run mold materials were mixed, degassed, and kept in a freezer. The catalyst was added to the mold mixture during the icing spray of the final run so that mold materials would be ready when the spray was completed. At the end of the run, after the tunnel was shut down, two of the blades were rotated 90 degrees so that the leading edge ice shape faced up. Wooden mold boxes were secured around the blades (Figure 3 ) and the mold materials were poured around the blades. The thermal mass of the test section assisted in keeping the temperature constant while the mold materials set up (the hardening process started approximately 10 minutes after the materials were poured into the mold boxes surrounding the blades). The molds were removed the next morning and the rotor blades cleaned for the next test run.

\section{Results}

\section{Test Conditions}

There were 71 icing tests runs during the contract portion of this test; these will be discussed here. The test matrix included a range of rotorcraft performance parameters for varied IRT conditions. The temperature range was $5^{\circ}$ to $-30^{\circ} \mathrm{C}$, the LWC range was 0.35 to $1.75 \mathrm{~g} / \mathrm{m}^{3}$, and the MVD range was 11 to 30 $\mu \mathrm{m}$. The nominal condition was $-15^{\circ} \mathrm{C}, 0.50$ $\mathrm{g} / \mathrm{m}^{3} \mathrm{LWC}$, and $15 \mu \mathrm{m} \mathrm{MVD}$. Icing times were from 45 to 250 seconds. Thrust, propulsive force, advance ratio, model rpm, and rotor control setting (constant lift vs. constant collective) were changed within the above tunnel conditions to provide a wide scope of performance mapping. Figure 4 shows a mapping of the meteorological conditions of the test. This is compared to the previous tests in 19892 and the FAA AC 29-2 Icing Envelope. It can be seen that this test filled in a significant portion of the envelope not acquired during the 1989 test.

As stated previously, the spray times ranged from 45 to 250 seconds for this test. Scale rotor testing uses these short icing times in order to simulate full scale conditions ${ }^{1}$. These spray times included the spray stabilization time. A plot of the J-W LWC data for a number of runs is given in Figure 5. Note that there was some rise time prior to reaching the target LWC (with the rise time generally increasing with the higher LWC runs). The spray condition remained relatively close to the desired LWC after the ramp up. It was found that the cloud reached the model about 10 seconds after spray on was initiated. 


\section{Discussion of Data}

Analysis of the data has not been completed; however, an initial assessment of data quality has been made based on three main attributes: repeatability, correct trending, and comparison with predictions. This paper will present some examples of the data in all three categories.

\section{Repeatability}

Repeatability has traditionally been a problem in natural icing flight testing because of the lack of control over meteorological conditions. Cloud formations are governed by nonlinear processes and are almost never repeated. Indeed, droplet distribution and concentration can vary widely under the same initial conditions. A major advantage of a facility such as the IRT is that cloud conditions within the test section can be controlled with a reasonable repeatability.

Figure 6 shows good repeatability for a constant collective condition which was repeated three times. Repeatability was also very good for the constant lift condition, as shown in Figure 7. Figure 8 shows a comparison of ice shape tracings taken at the same radial location for a repeat condition. It can be seen that the ice shape was repeated reasonably well, with some minor differences. Part of the scatter was due to the ice tracing procedure employed. In general, it is felt that the repeatability of the test was very good.

\section{Trends}

Icing is a function of many variables, such as LWC, MVD, temperature, velocity, etc. The performance of helicopter rotors are also dependent on many factors. Thus, a rigorous test of the effects of icing on the performance of a helicopter main rotor requires the isolation of many different parameters. For this test, the main parameters of interest were:
1) Temperature
2) $\mathrm{LWC}$
3) MVD

4) Rotor Lift Condition (Constant Collective vs. Constant Lift)

5) Main Rotor Lift $\left(\mathrm{C}_{\mathrm{L}} / \sigma\right)$

6) Advance Ratio $(\mu)$

7) Rotor Tip Speed $(\Omega R)$

8) Shaft Angle ( $\alpha$ )

For the purposes of this report, results showing the effects of temperature, LWC, rotor lift control mode, main rotor lift, and droplet size will be presented.

\section{Lift Control Mode}

The main rotor lift during the icing encounter was controlled in two ways for this test; constant collective mode and constant lift mode. In the constant collective mode, the collective pitch of the rotor was set at the beginning of the icing spray and held constant during the icing event. While the rotor was iced up and the rotor lift degraded, the pilot maintained a trimmed flying condition but made no effort to keep lift constant. In the constant lift mode, the collective pitch of the rotor was increased automatically during the icing spray to maintain a constant lift throughout the icing event. Figure 9 shows a torque rise comparison between two runs in which the only difference is the lift control mode of the rotor. It can be seen that the constant lift mode has a higher torque rise for the same condition than the constant collective mode because of the collective pitch being increased.

\section{Temperature}

One of the main areas of concern for this test was that of temperature effects, particularly near freezing. Tests at various temperatures were performed for both the constant lift and constant collective control modes. Figure 10 shows the torque rise as a function of icing time for a temperature range of $-25{ }^{\circ} \mathrm{C}$ to $-12{ }^{\circ} \mathrm{C}$ with the rotor in the constant collective mode. It can be seen that the torque rise increases as temperature increases. This is because as the temperature increases, the accreted ice shape on the outer portion of the rotor blades changes from rime to glaze, 
increasing the performance penalties. This is supported by Figure 11. Here, the type of ice at various radial locations has been plotted as a function of temperature. The transition location from rime to glaze along the outer portion of the blade moved inboard as temperature increases. This is further illustrated in Figure 12, which shows ice tracings taken at a spanwise extent of $90 \%$ for two different temperatures. The $-25^{\circ} \mathrm{C}$ tracing was clearly a rime shape while the $-12^{\circ} \mathrm{C}$ tracing was glaze. So, for this temperature range the torque rise was mainly a function of transition location.

Figure 13 shows the torque rise as a function of time for a temperature ranging from $-12{ }^{\circ} \mathrm{C}$ to $-2{ }^{\circ} \mathrm{C}$ with the rotor in constant collective mode. For this temperature range it can be seen that the torque rise decreases as temperature increased, the opposite of Figure 10. The torque rise decreased because, in this temperature range, the radial extent of icing decreased as the temperature approached that of freezing. Less ice was accreting on the rotor, reducing the performance penalties. This is shown in Figure 11 where the spanwise extent of ice decreases from $96 \%$ to $35 \%$ as the temperature increased from $-12{ }^{\circ} \mathrm{C}$ to $-2{ }^{\circ} \mathrm{C}$. So, for this temperature range the torque rise was mainly a function of icing radial extent. Figures 10 and 13 indicate that, for this test configuration the "worst" case temperature in terms of torque rise was $-12{ }^{\circ} \mathrm{C}$. This corresponds to the 1989 PFM test which indicated a "worst" case temperature of between $-15{ }^{\circ} \mathrm{C}$ and $-10{ }^{\circ} \mathrm{C}$. Temperature trending was also done for the constant lift mode with similar results to those shown for the constant collective case. These results are shown in Figures 14 and 15.

\section{Liquid Water Content}

Another major parameter driving the icing process is LWC. For the case where the rotor speed is constant in the absence of shedding, the general trend is the higher the LWC, the higher the accretion rate and associated performance penalties. Figure 16 shows a plot of torque rise as a function of icing time for various LWCs for the rotor in the constant collective mode. In the first 40 seconds of icing it can be seen that the slope of the torque rise was greater for the higher LWCs, as would be expected. This plot also illustrates just how strongly ice shedding from the rotor can dominate the torque rise. After about 40 seconds of icing, shedding effects began to come into play. The highest LWC $\left(1.5 \mathrm{~g} / \mathrm{m}^{3}\right)$ shed first, at about 40 seconds. The next highest LWC $\left(1.25 \mathrm{~g} / \mathrm{m}^{3}\right)$ began to shed at about 50 seconds. Finally, the lowest LWC $\left(1.0 \mathrm{~g} / \mathrm{m}^{3}\right)$ did not begin to shed until about 65 seconds. The lowest LWC actually had the highest torque rise for part of the icing encounter, because of the effects of shedding. A similar trend is shown in Figure 17, which shows the effect of LWC for the constant lift mode of operation. Here again, the slope of the torque rise increased with $\mathrm{LWC}$. In this case, the two highest LWCs $\left(1.25\right.$ and $\left.1.5 \mathrm{~g} / \mathrm{m}^{3}\right)$ showed approximately the same rate of torque rise. Shedding effects began to occur at about 35 seconds of icing, slightly earlier than in the constant collective case. Again, because of the delayed shedding, the case with a LWC of 1.0 $\mathrm{g} / \mathrm{m}^{3}$ actually showed higher torque rise late in the run than that of the higher LWC cases. The slope of the $0.75 \mathrm{~g} / \mathrm{m}^{3}$ case was low enough that its torque rise stayed below that of the higher LWC cases, even though it did not shed until very late in the encounter (about $75 \mathrm{sec}$ ).

\section{Main Rotor Lift}

All results for main rotor lift have been non-dimensionalized into the term $\mathrm{C}_{\mathrm{V}} / \sigma$ where,

and

$$
C_{L}=\frac{L}{\rho \pi R^{2}(\Omega R)^{2}}
$$

$$
\sigma=\frac{b c}{\pi R}
$$

Figure 18 shows the torque rise as a function of icing time for various rotor lift conditions $\left(C_{L} / \sigma\right)$ in the constant collective mode. It can be seen that there was a slight trend of higher torque rise for higher $\mathrm{C}_{\mathrm{L}} / \sigma$. This is an angle of attack effect. The higher lifts were obtained by 
increasing the collective pitch of the rotor. The power increment is greater for higher angles of attack. Figure 19 shows the same trend for the constant lift mode. The effect seems slightly more pronounced than in the constant collective mode. This is because the collective pitch (and hence, local angle of attack) increases during the icing event in the constant lift mode.

\section{Droplet Size}

Droplet size affects the icing process in that larger droplets will tend to impinge further back on the airfoil, and thus cause more severe performance penalties. This trend is born out in Figure 20. Here, the torque rise is shown to be higher for the larger droplet size. Figure 21 shows ice tracings taken at $\mathrm{r} / \mathrm{R}=40 \%$ for an MVD of 15 and $20 \mu \mathrm{m}$. It can be seen (particularly on the upper surface) that the impingement limits were further back for the 20 $\mu \mathrm{m}$ case. It was difficult to draw any conclusions about the lower impingement limits. The tracings often had arbitrary stopping points here because frost formations on the lower surface often masked a well defined ending to the ice shape. Figure 22 shows the ice tracings taken for the same two runs at the $70 \%$ radial location. Here it can been seen that the glaze horn angle was further back for the higher droplet size. In a similar fashion, the secondary feather formation was further back for the higher droplet size.

\section{Comparison With Predictions}

Theoretical models can be used to predict accretion, shedding, and rotor performance. This paper will present a few representative results in the area of rotor performance prediction. The Sikorsky Aircraft Generalized Rotor Performance (GRP) code was used to compute the rotor performance. An icing subroutine linked to GRP was used to predict the changes in the rotor performance due to icing. This subroutine makes use of a rotorcraft icing prediction method based on correlation studies as described in Reference 4. The method can be broken down into two regimes. The first regime exists prior to the onset of rotor shedding, thus limiting the analysis to ice accretion only. The second regime exists after the onset of rotor shedding. Shedding is a somewhat random phenomena making correlation in this regime difficult.

The correlation predicts (among other things) incremental rotor lift $\left(\Delta \mathrm{C}_{\mathrm{L}} / \sigma\right)$ and incremental rotor torque $\left(\Delta \mathrm{C}_{\mathrm{Q}} / \sigma\right)$. Depending on the lift control mode the collective pitch was either held constant at the predicted clean rotor trim solution (constant collective) or allowed to increase so that lift remained constant at the predicted clean rotor trim solution (constant lift). The build-up in LWC that occurred during the start of the icing encounter (Figure 5) has been ignored.

Figure 23 shows a comparison between the experimental and predicted torque rise for the constant collective nominal condition. It can be seen that the comparison is excellent early in the icing encounter $(<40 \mathrm{sec})$. As the onset of shedding begins (>40 sec), the correlation slightly overpredicts the torque rise. Figures 24 and 25 compare the predicted temperature trending to the experiment. The current correlation slightly overpredicts the warm temperature cases at an icing time of 20 seconds. The correlation is in good agreement at 40 seconds, but is optimistic at higher icing times. It is possible that the overprediction at 20 seconds is partly due to the fact that the LWC rise time is ignored in the correlation. At the colder temperatures, the correlation underpredicts slightly at 20 seconds and is conservative at 40 seconds.

\section{Summary and Conclusions}

To date, the examination of the data from this test has proven encouraging. Preliminary assessments indicate that the quality of the data is excellent. The changes in torque were very repeatable for both control modes (constant lift and constant collective). All of the trending effects of variables such as temperature, $\mathrm{LWC}, \mathrm{MVD}$, and $\mathrm{C}_{\mathrm{L}} / \sigma$ behaved as expected. Comparison of test results were made with the Sikorsky Generalized Rotor Performance (GRP) code. Good agreement was generally seen between the experimental 
data and the predictions.

In the near term the goal is to complete a detailed analysis of the whole data set. In depth correlation studies are to be performed in order to improve the current prediction capabilities. Molds taken during the test will be used to make castings for simulated ice experiments in a dry air wind tunnel. These experiments will involve detailed performance mapping of a select few ice shapes in order to determine the fidelity of the simulated icing test method.

Long term goals include a coordinated program involving further model icing tests in conjunction with a full-scale rotorcraft icing flight test. This follows a logical progression for development and verification of the model rotor test techniques and analytical methods.

\section{$\underline{\text { References }}$}

1 Flemming, R.J., Bond, T.H., and Britton, R.K., "Results of a Sub-Scale Model Rotor Icing Test," AIAA Paper 91-0660 (Also NASA TM 103709), January 1991.

2 Flemming, R.J. and Saccullo, A., "Tests of a Model Main Rotor in the NASA Lewis Research Center Icing Research Tunnel," NASA CR 189071 (Also SER510354), December 1991.

3 Britton, R.K. and Bond, T.H., “A Review of Ice Accretion Data From a Model Rotor Icing Test and Comparison With Theory," AIAA Paper 91-0661 (Also NASA TM 103712), January 1991.

$4 \quad$ Flemming, R.J. and Lednicer D.A., "High Speed Ice Accretion on Rotorcraft Airfoils," NASA CR 3910, August 1985. 


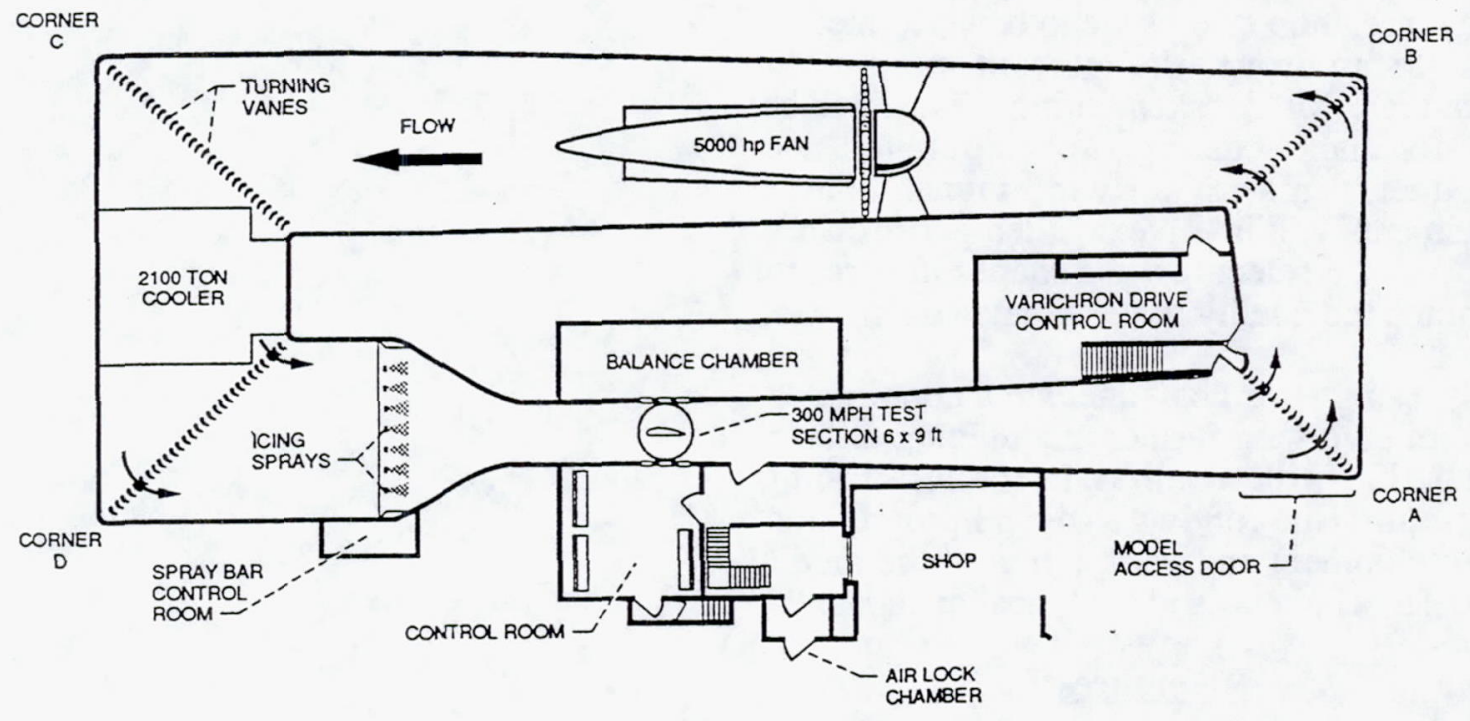

Figure 1. Overview of NASA Lewis Icing Research Tunnel.

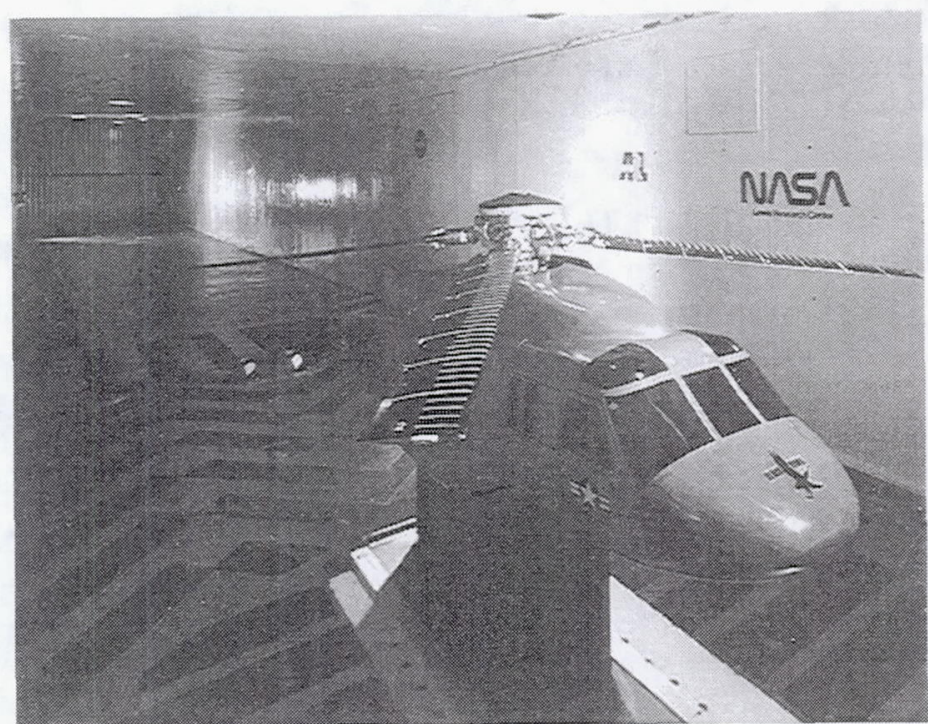

Figure 2. Sikorsky Model Rotor Test Rig in IRT. 


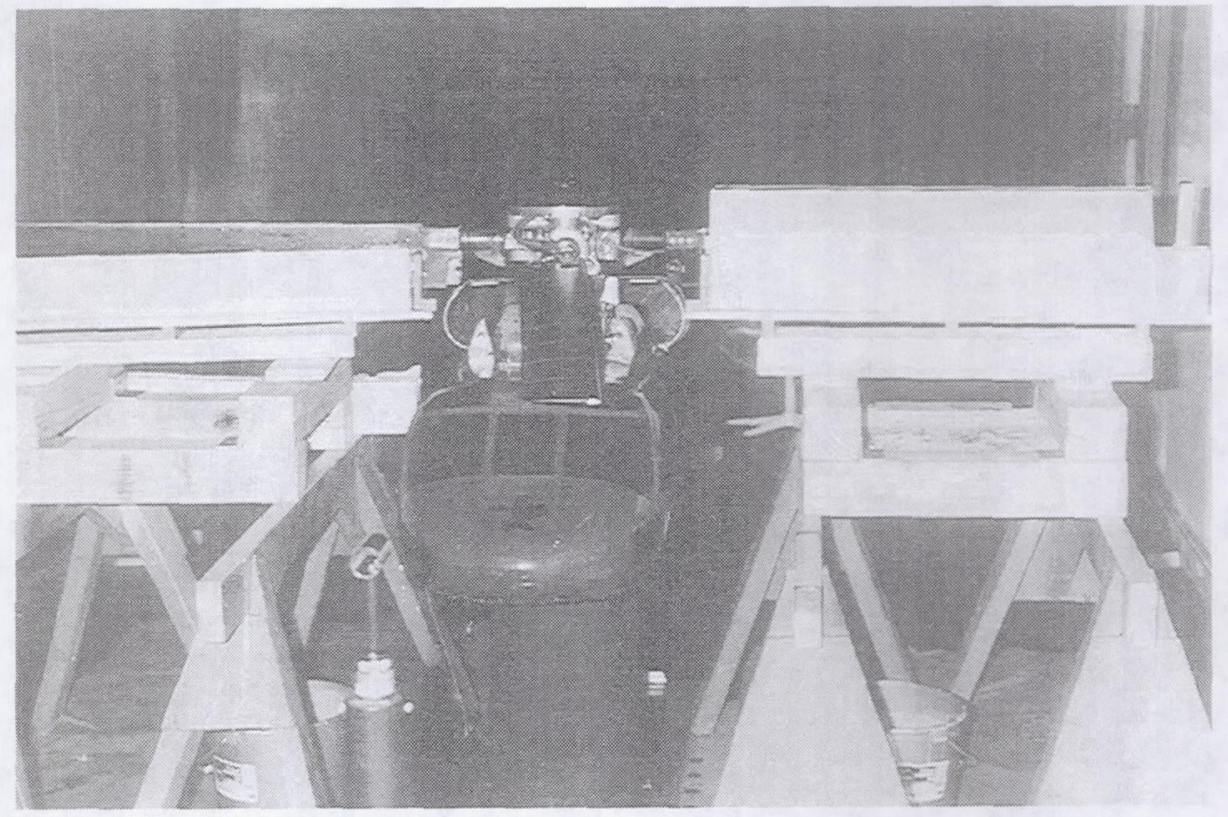

Figure 3. Molding procedure.

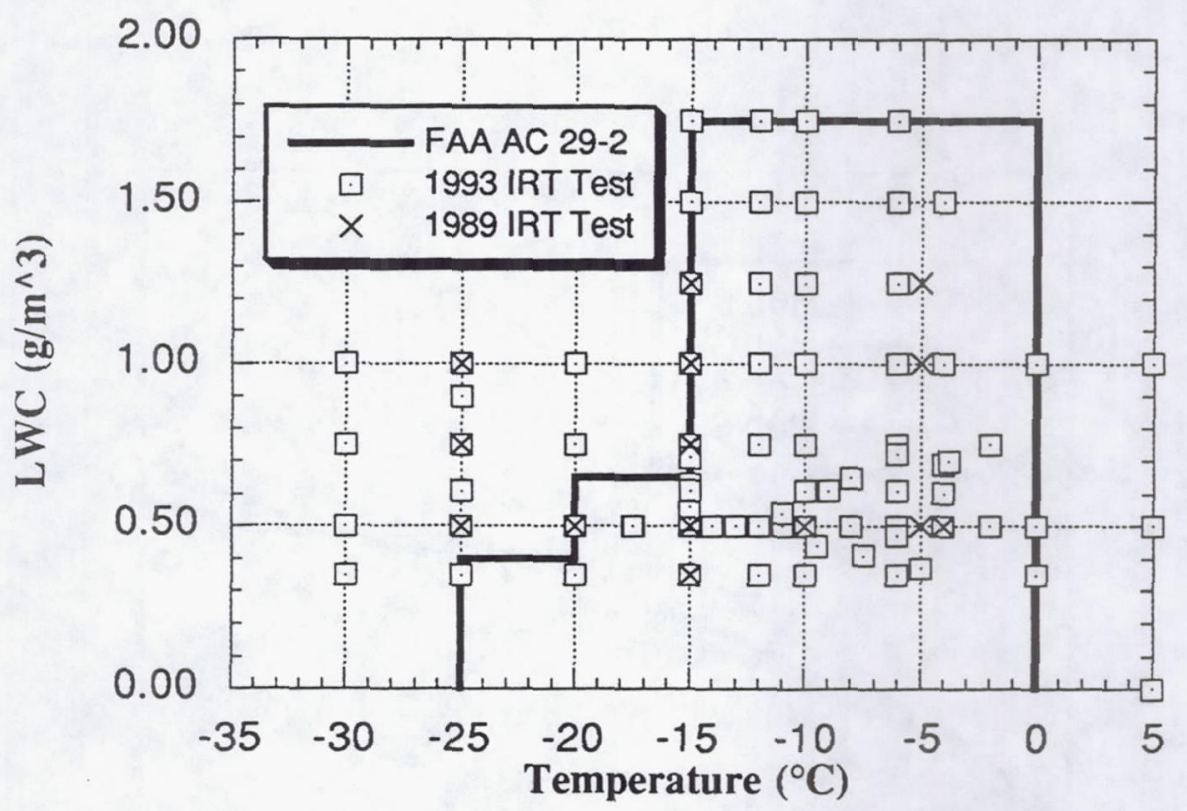

Figure 4. Icing test points for 1989 and 1993 tests. 


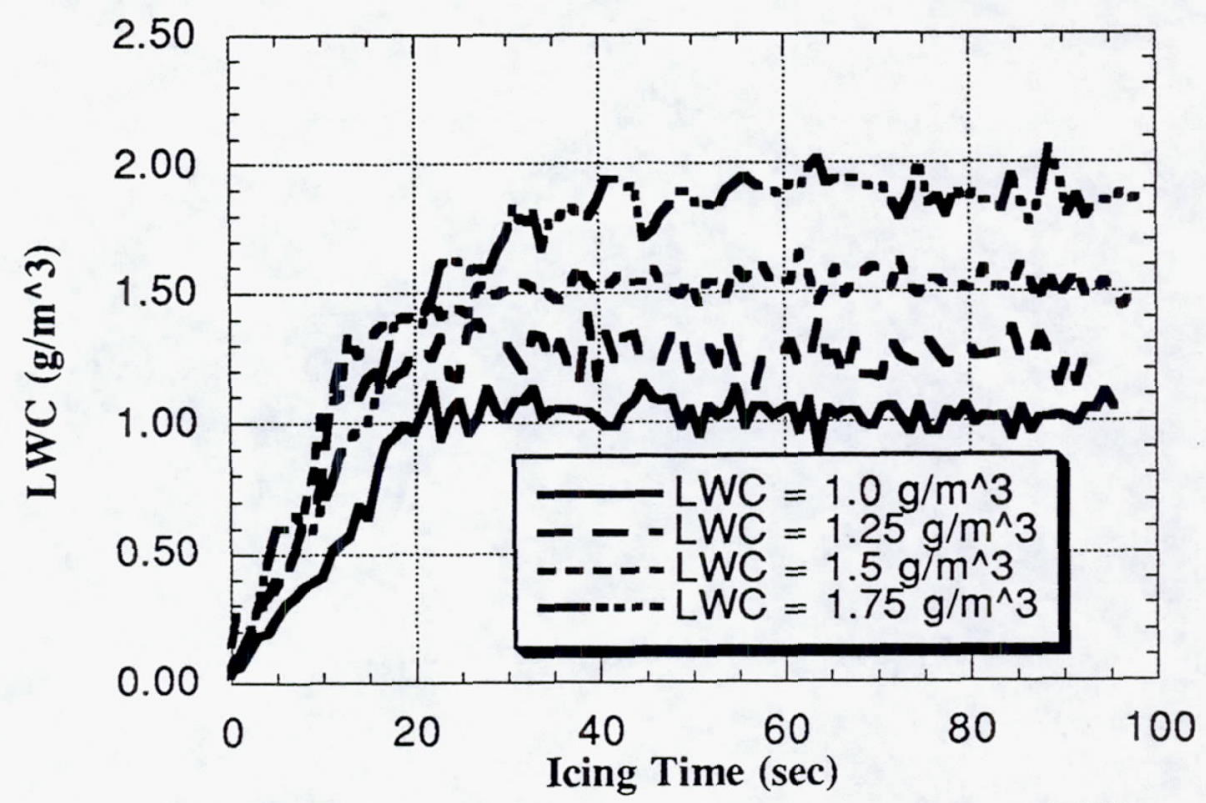

Figure 5. Test section spray rise time for various LWC's.

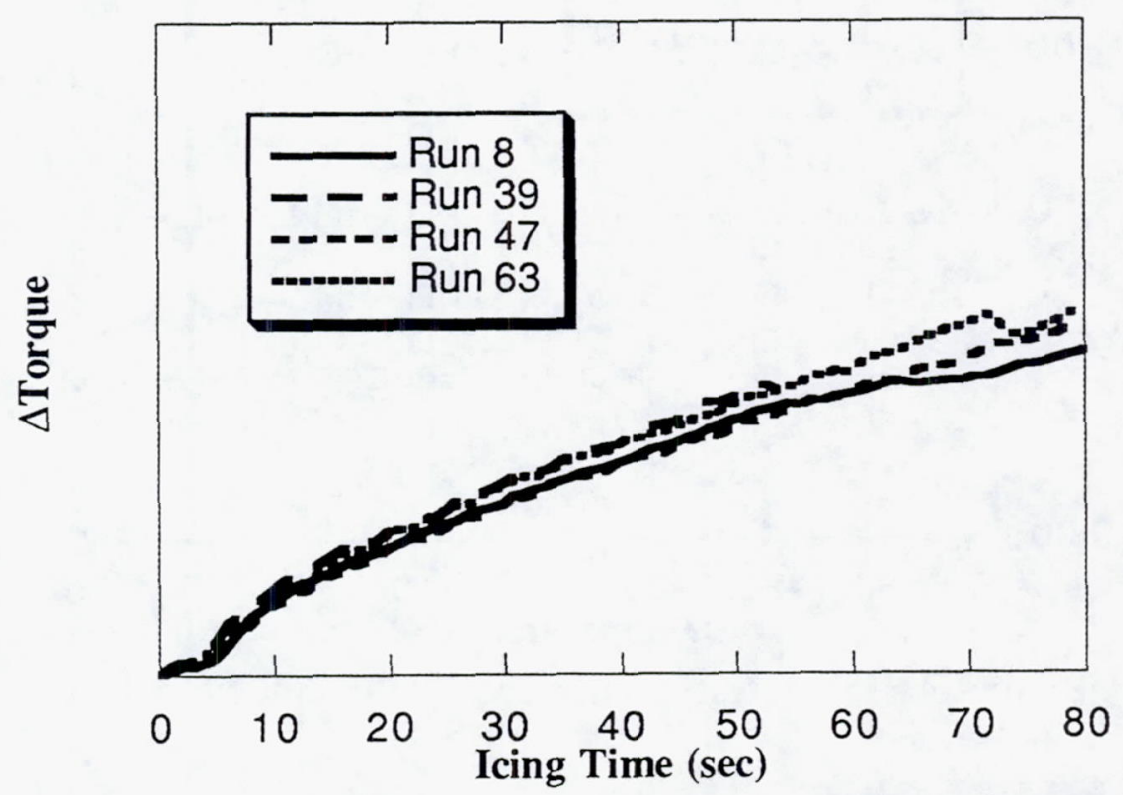

Figure 6. Torque rise repeatability for constant collective mode. 


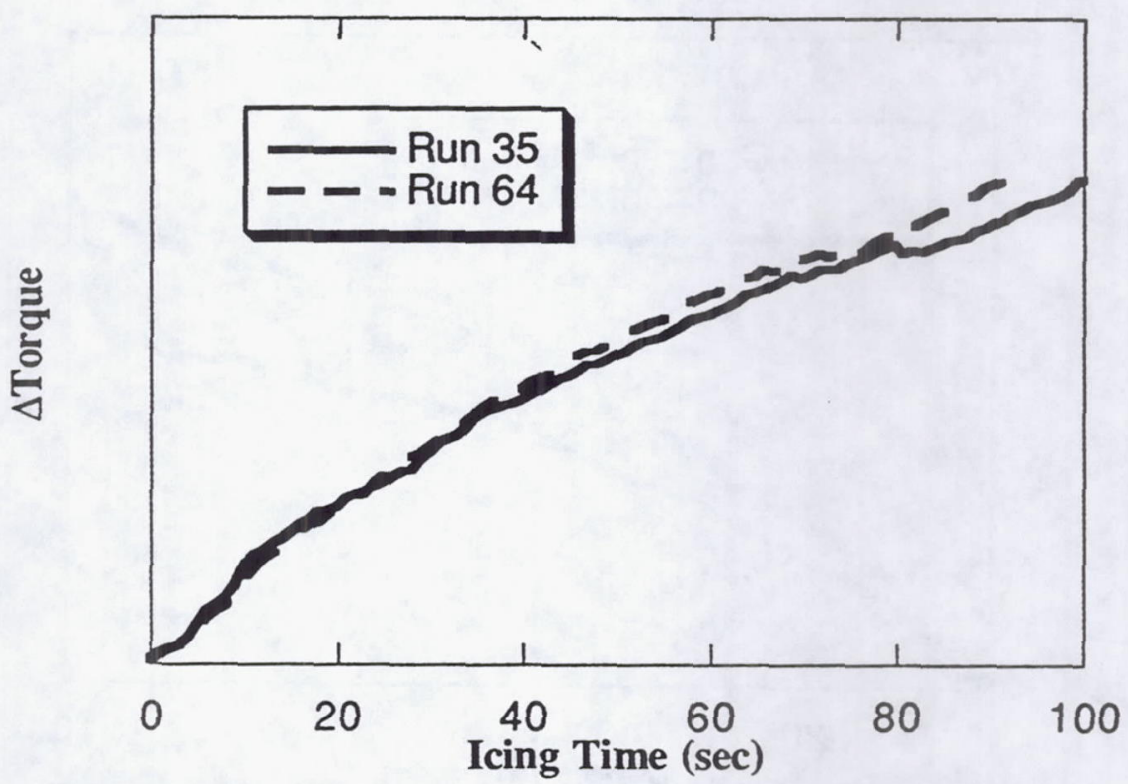

Figure 7. Torque rise repeatability for constant lift mode.

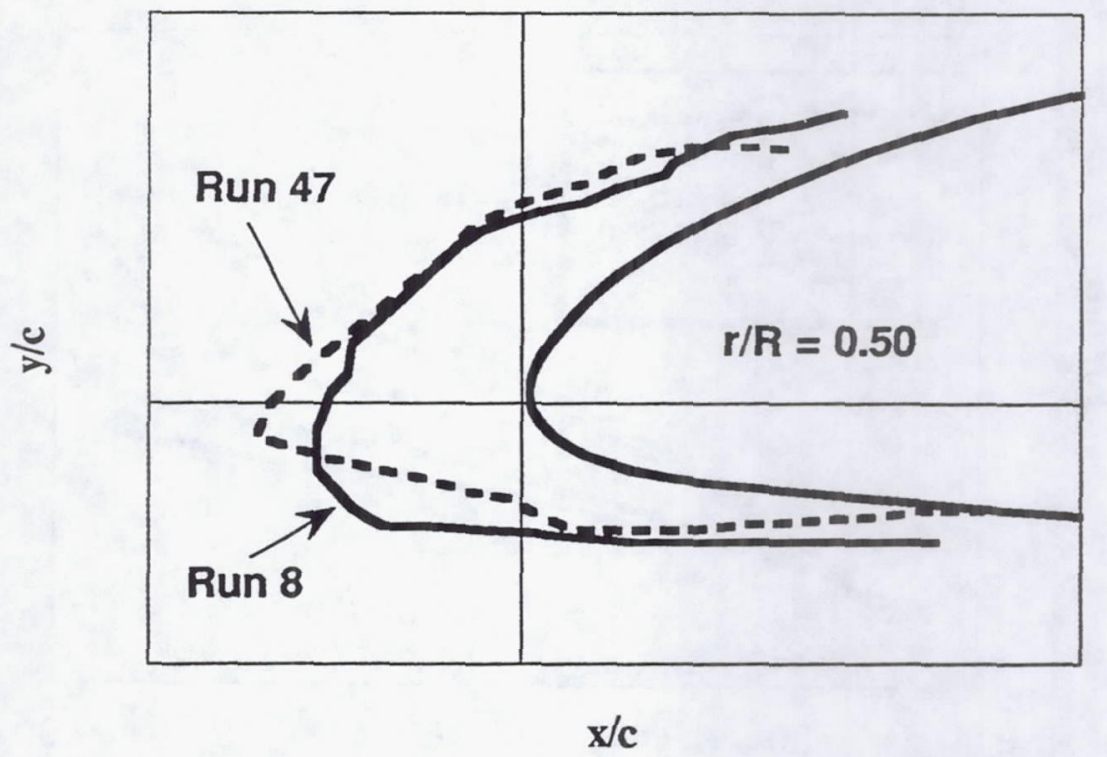

Figure 8. Ice shape repeatability for constant collective mode. 


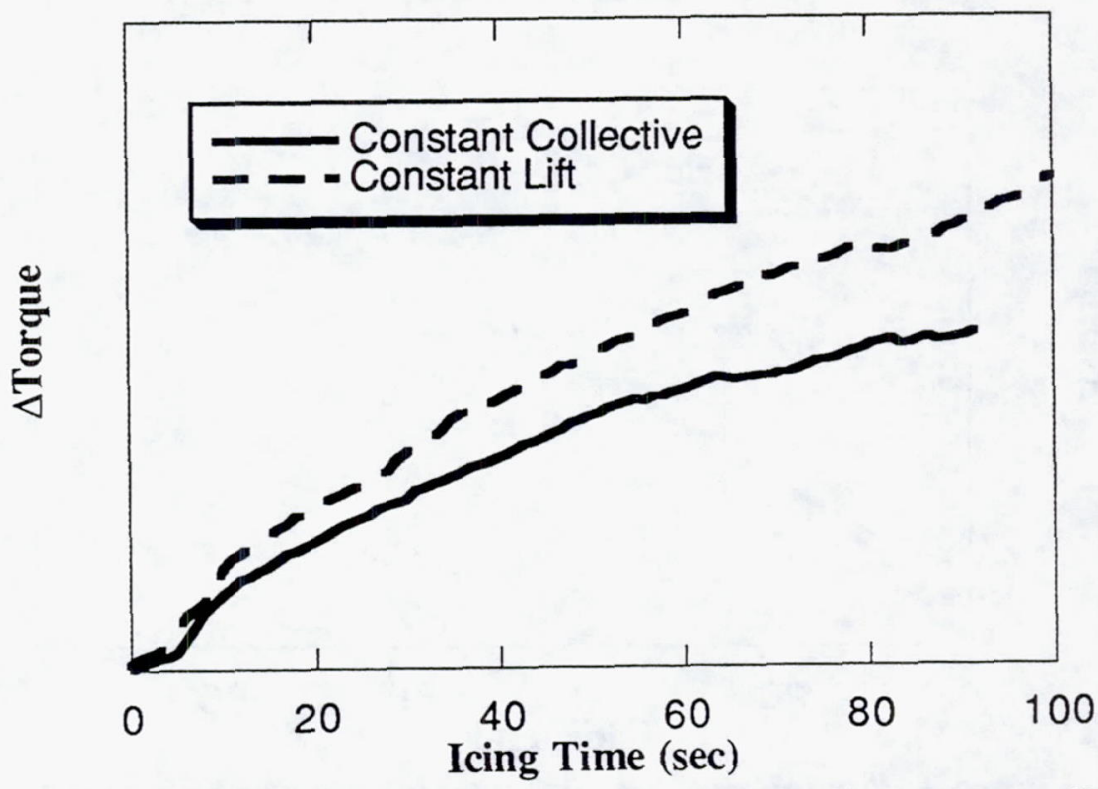

Figure 9. Torque rise comparison between constant lift and constant collective mode.

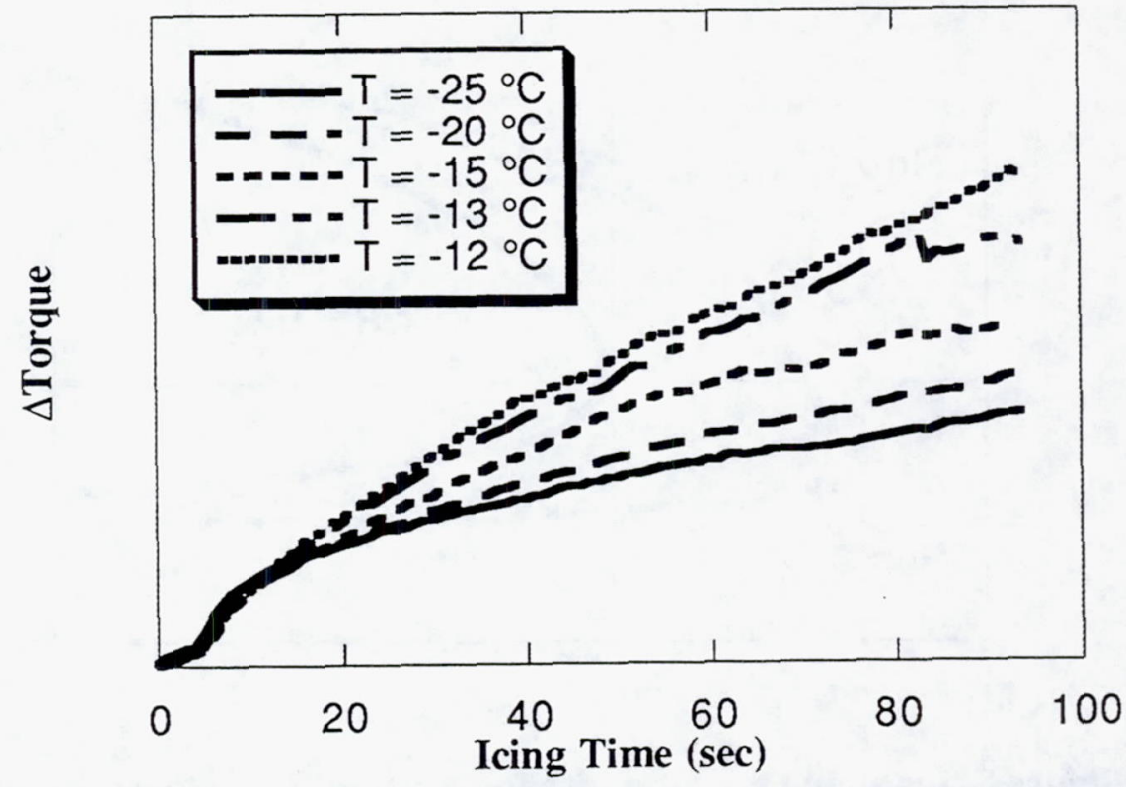

Figure 10. Torque rise trend with "cold" temperatures (constant collective mode). 


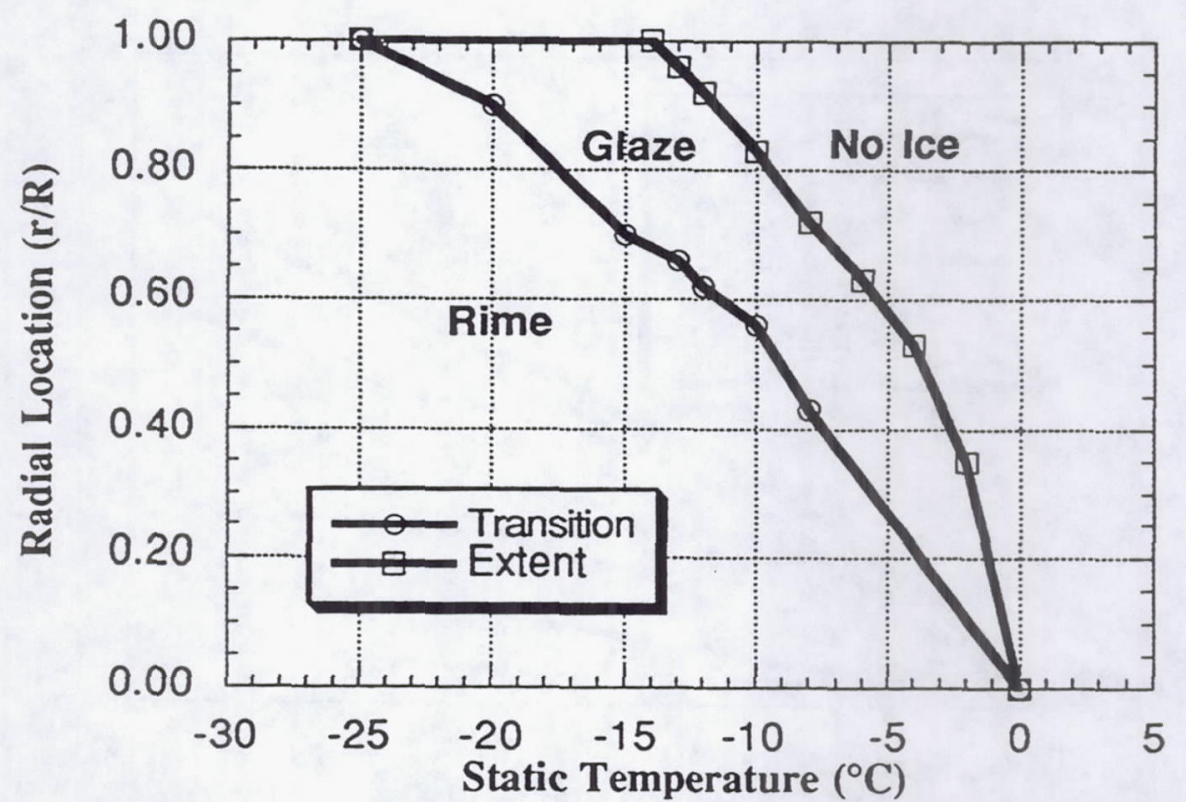

Figure 11. Experimental ice type and extent for anchor point conditions (constant collective mode).

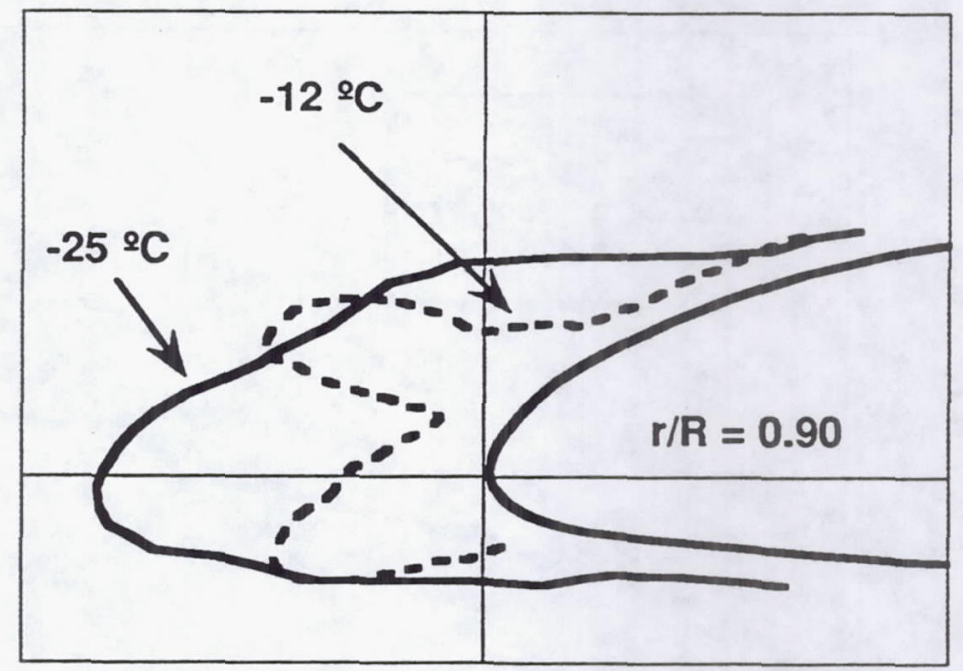

Figure 12. Ice shape tracing comparison at $90 \%$ radial location (constant collective mode). 


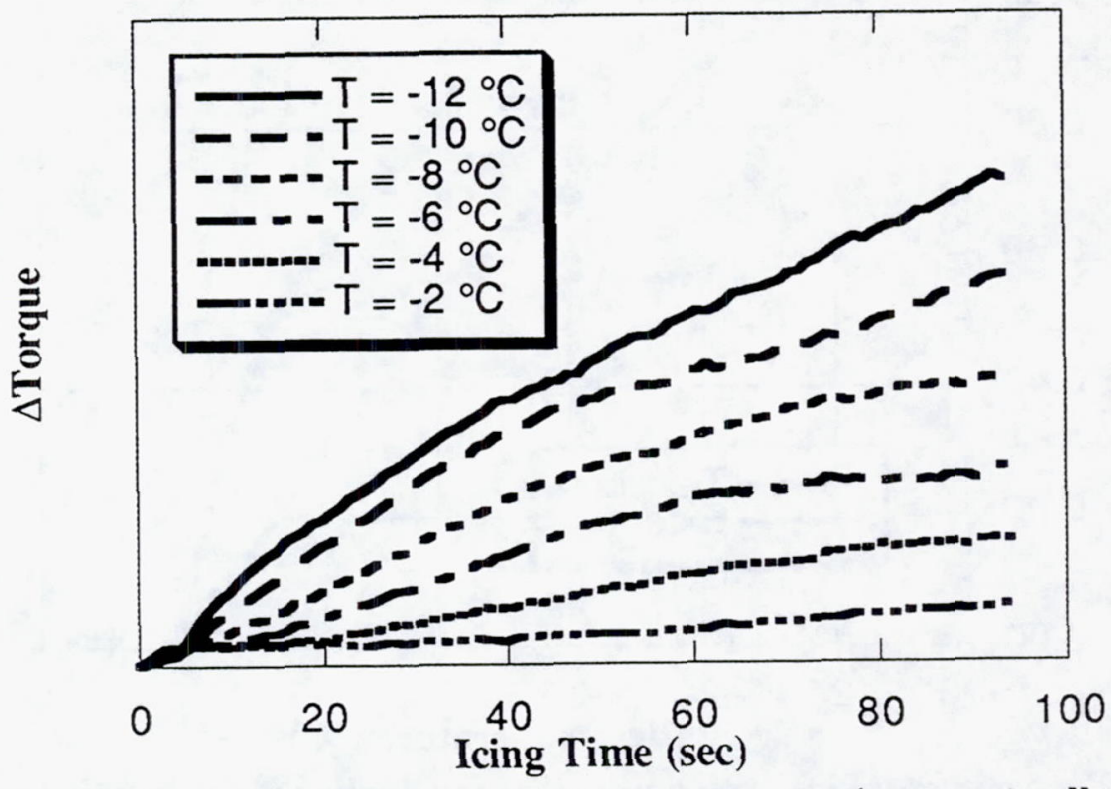

Figure 13. Torque rise trend with "warmer" temperatures (constant collective mode).

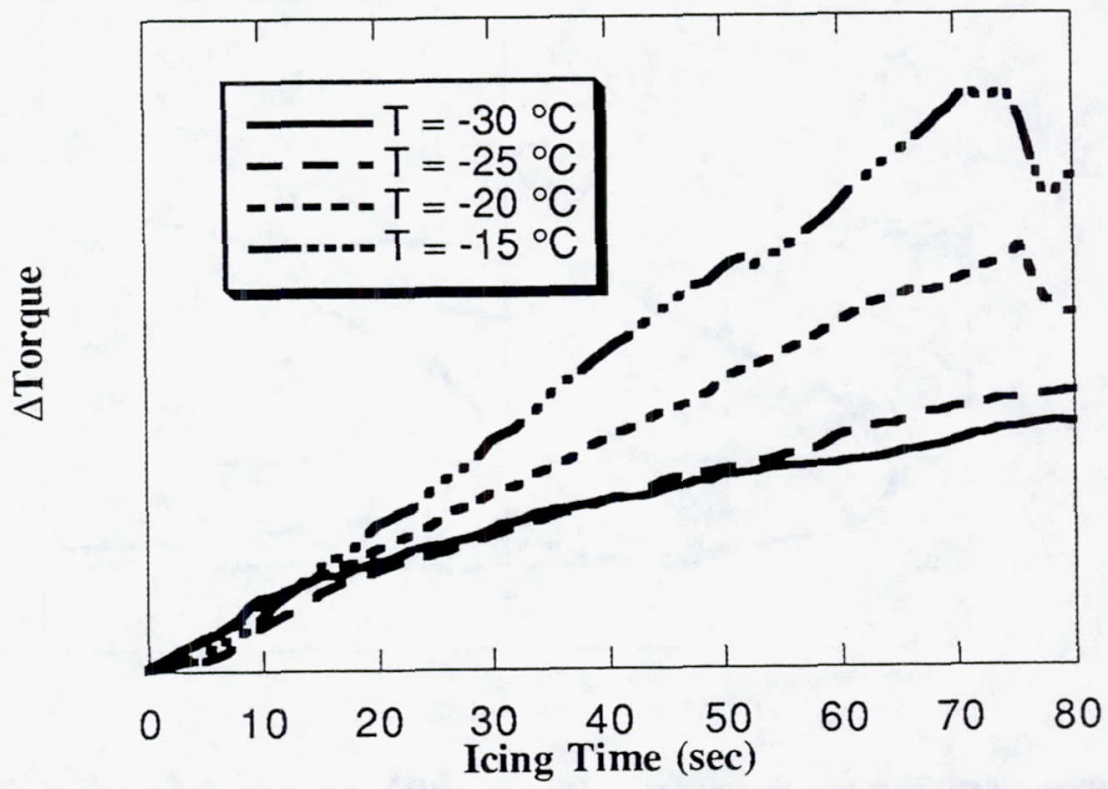

Figure 14. Torque rise trend with "cold" temperatures (constant lift mode). 


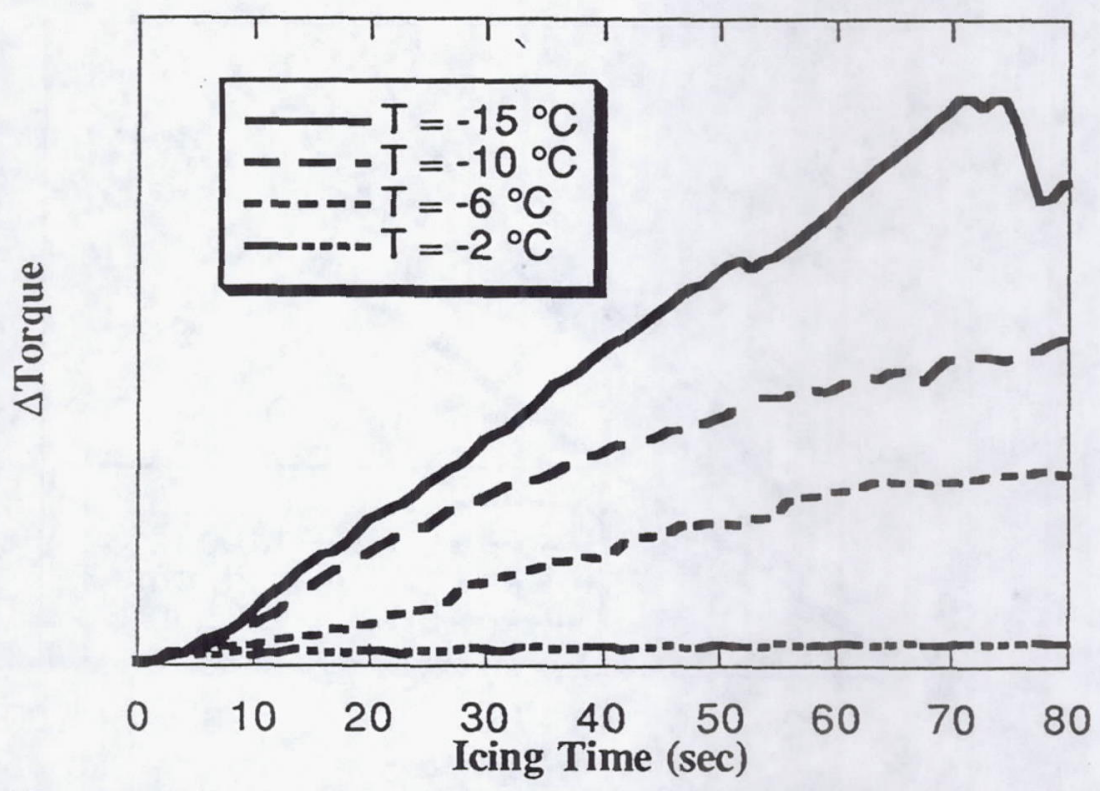

Figure 15. Torque rise trend with "warmer" temperatures (constant lift mode).

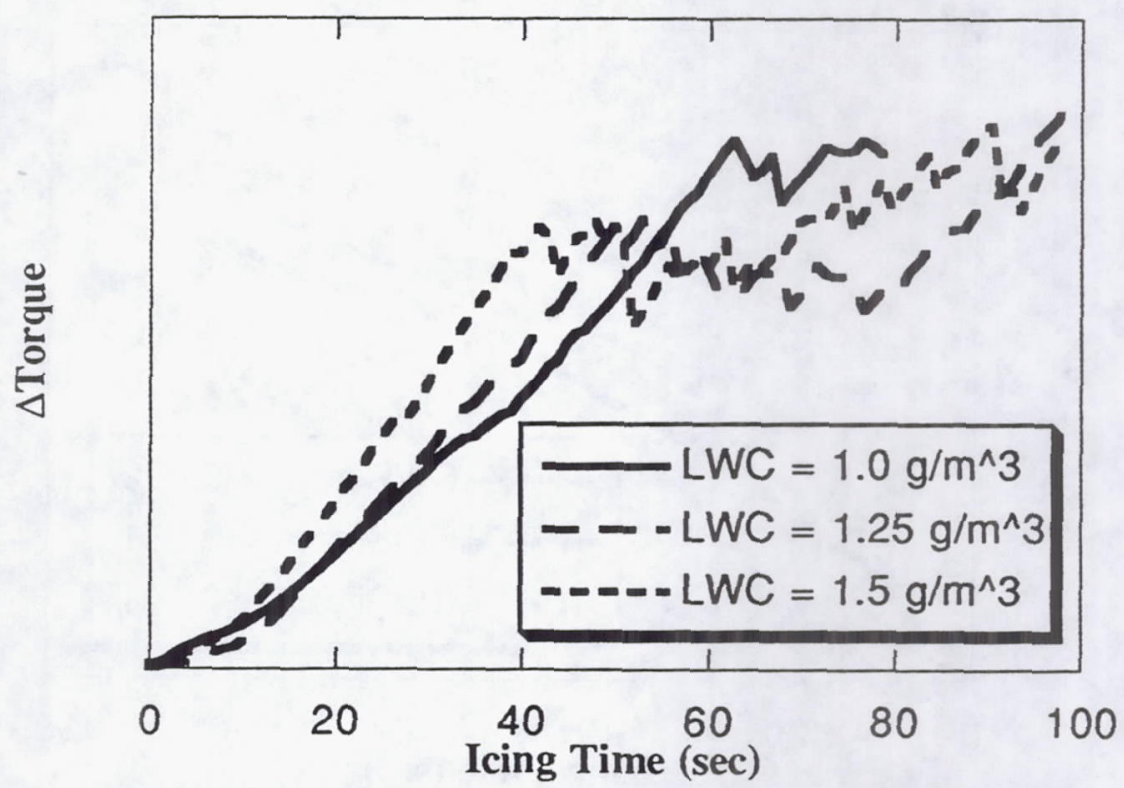

Figure 16. Torque rise trend with LWC (constant collective mode). 


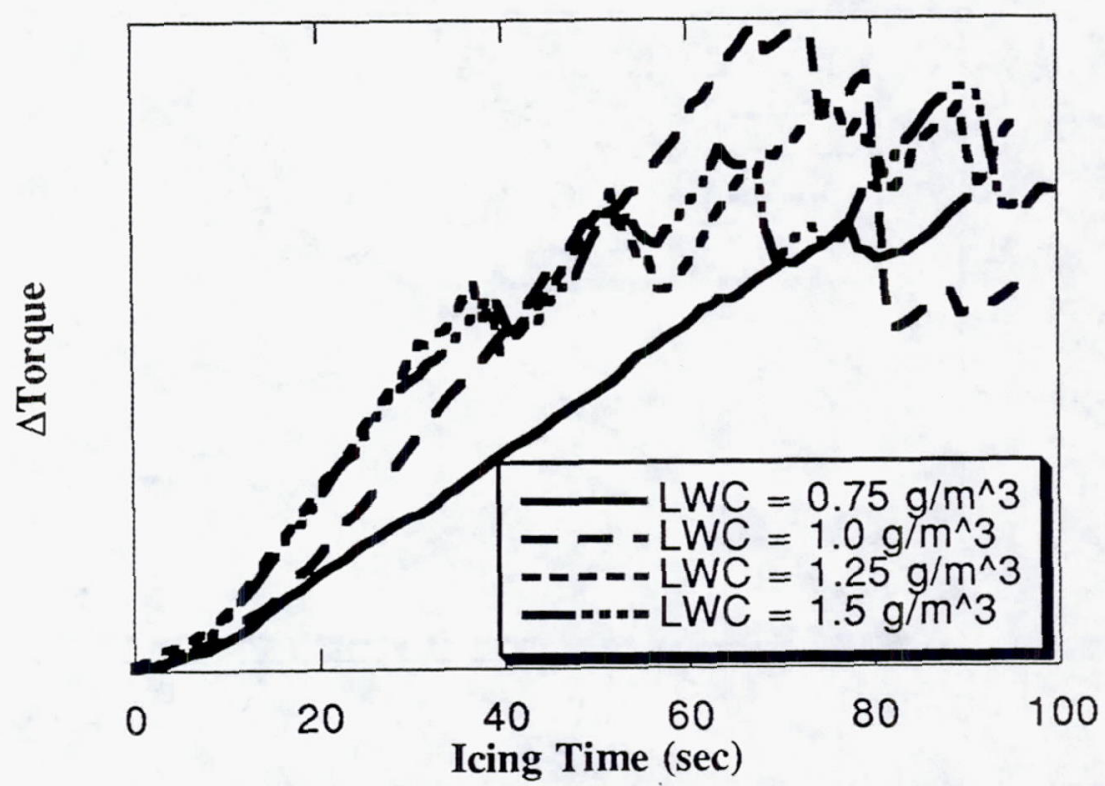

Figure 17. Torque rise trend with LWC (constant lift mode).

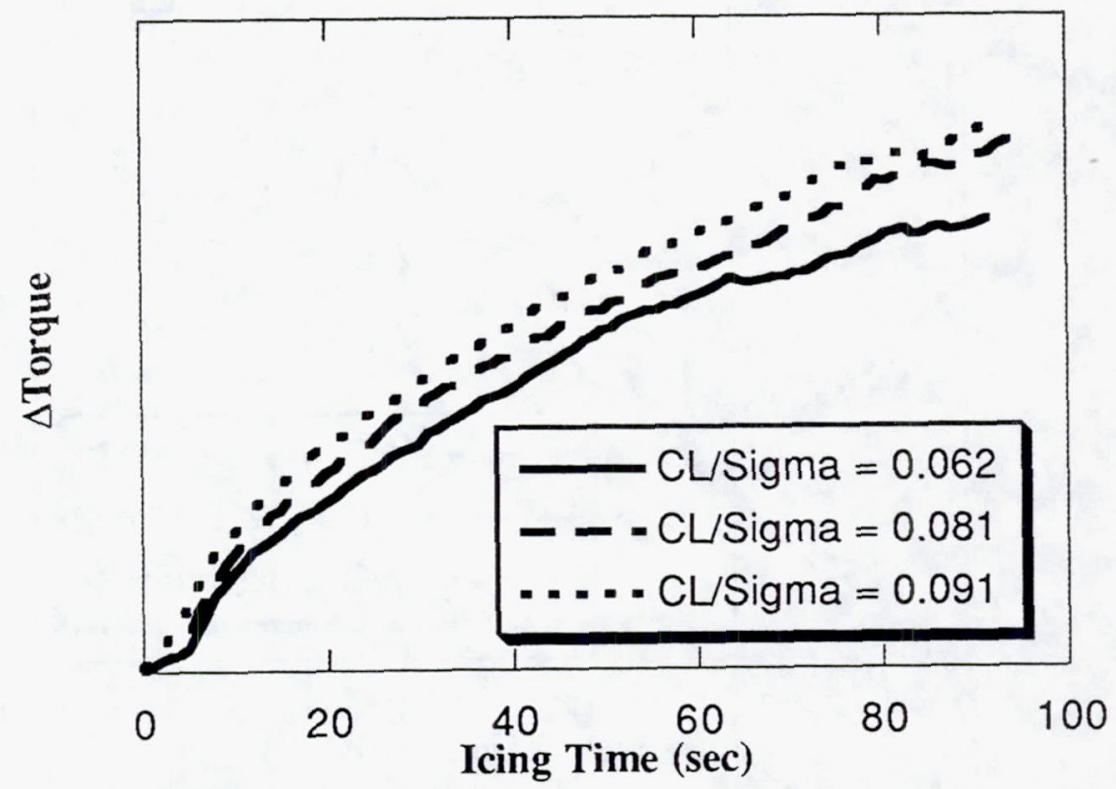

Figure 18. Torque rise trend with $C_{L} / \sigma$ (constant collective mode). 


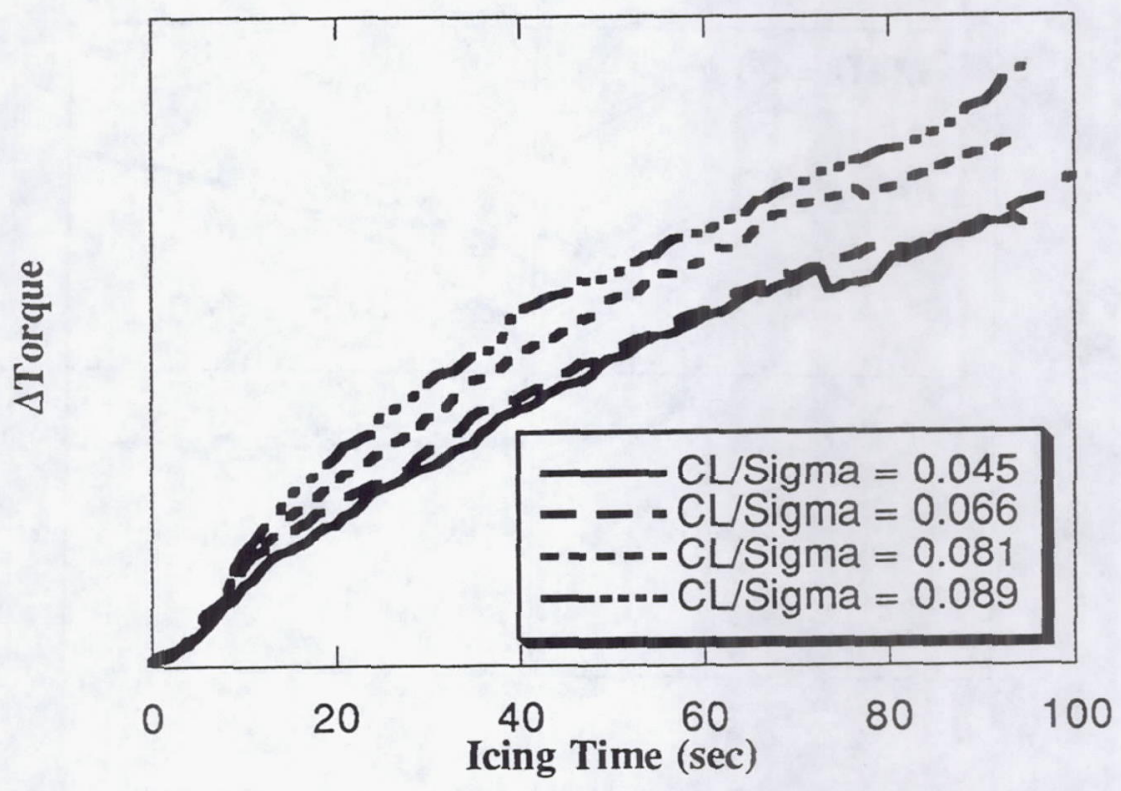

Figure 19. Torque rise trend with $\mathrm{C}_{\mathrm{L}} / \sigma$ (constant lift mode).

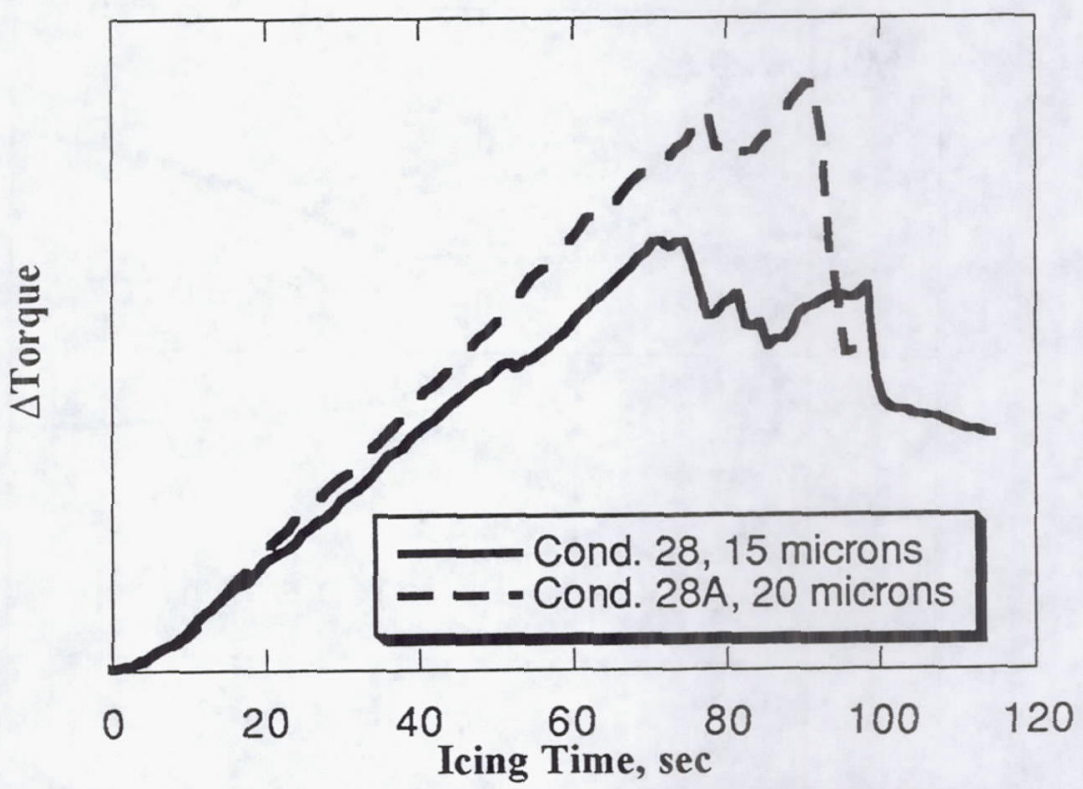

Figure 20. Torque rise trend with MVD (constant lift mode). 


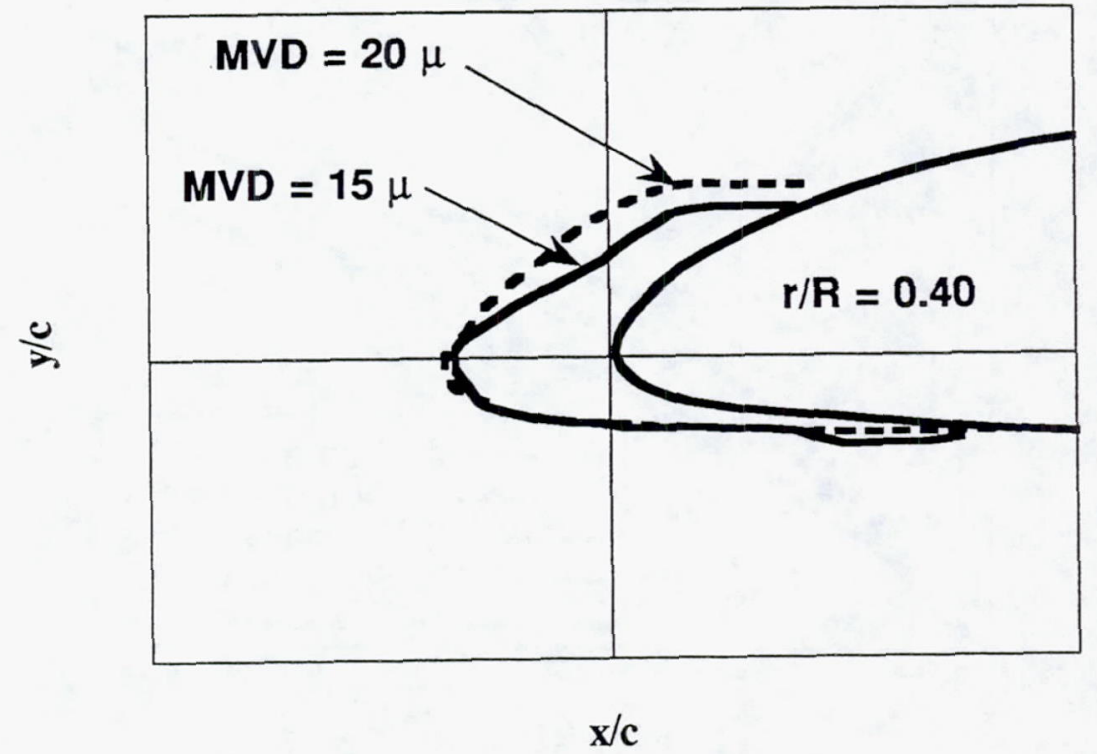

Figure 21. Comparison of ice shape tracings for radial location of $40 \%$ (constant lift mode).

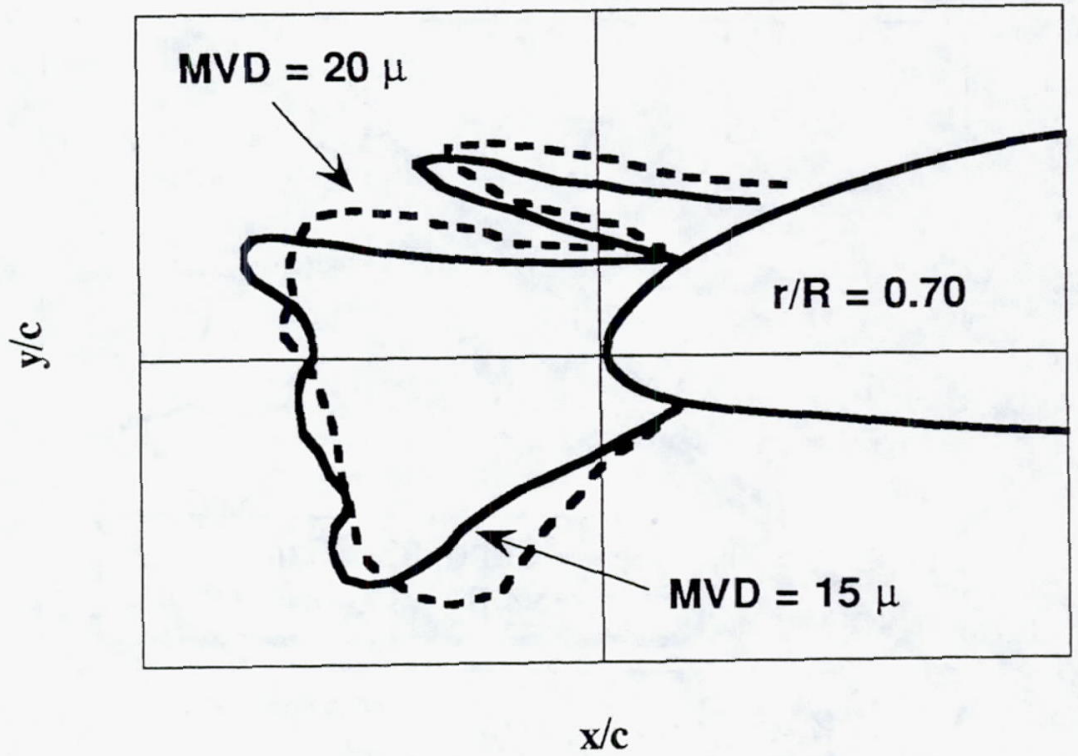

Figure 22. Comparison of ice shape tracings for radial location of $70 \%$ (constant lift mode). 


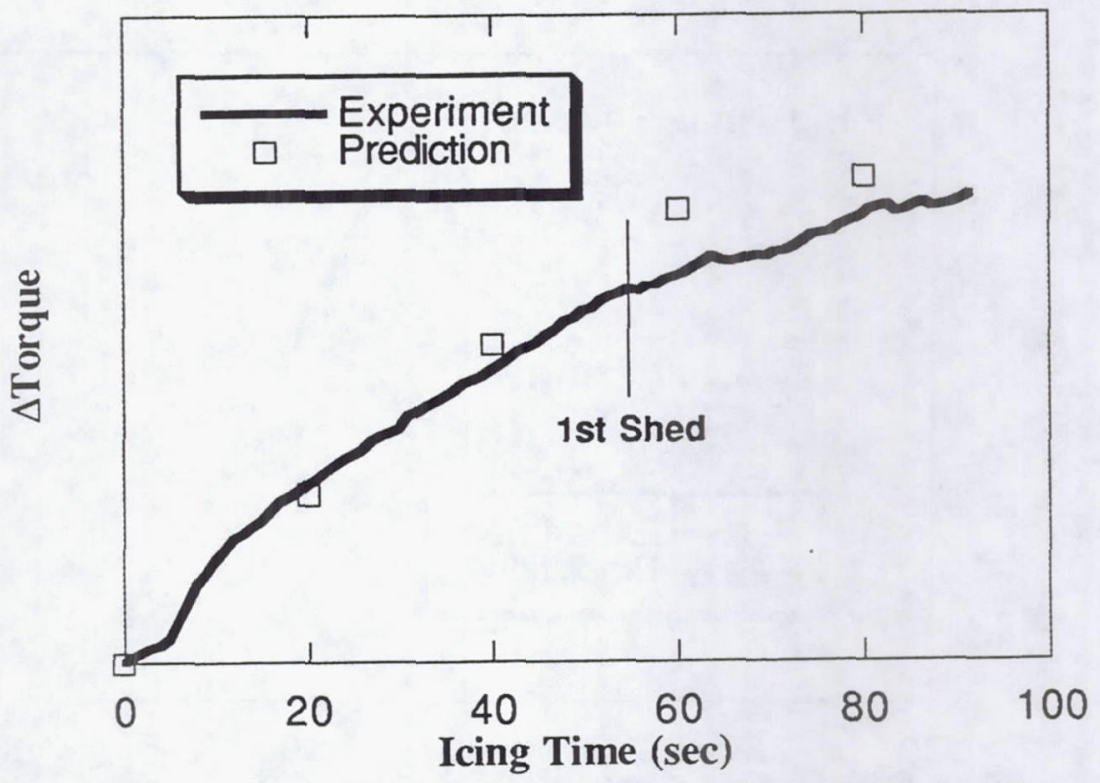

Figure 23. Comparison between experiment and theory for torque rise (constant collective mode).

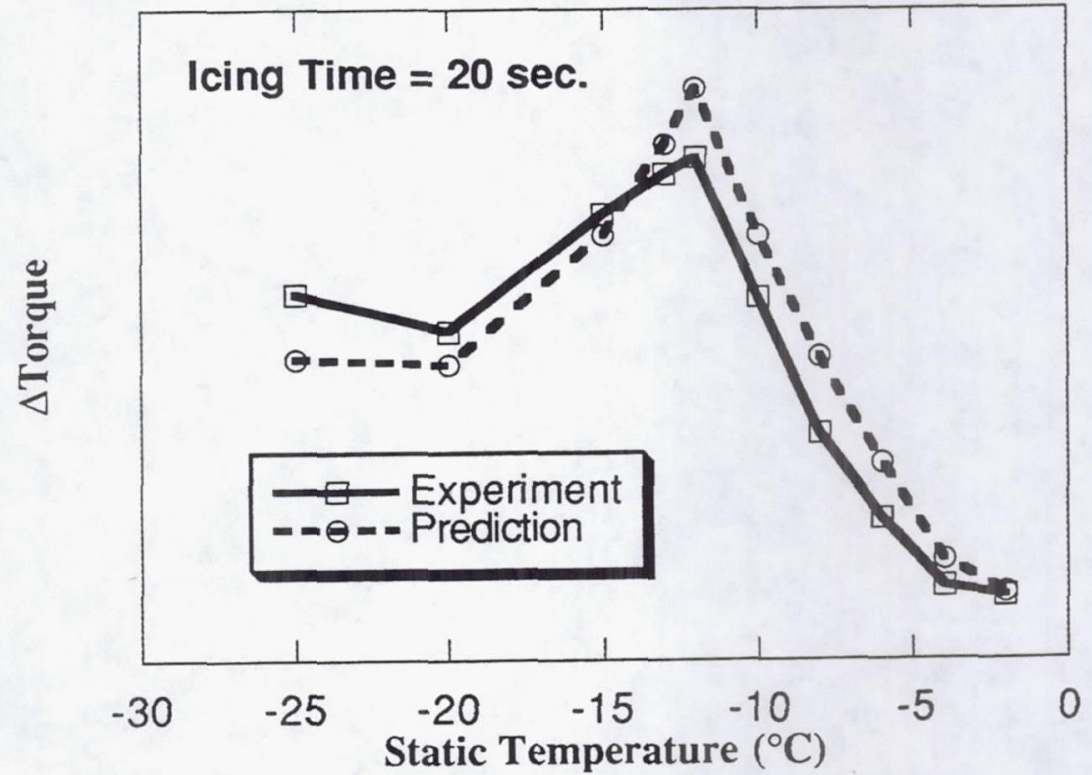

Figure 24. Comparison between experiment and theory for torque rise as a function of temperature for an icing time of $\mathbf{2 0}$ seconds (constant collective mode). 


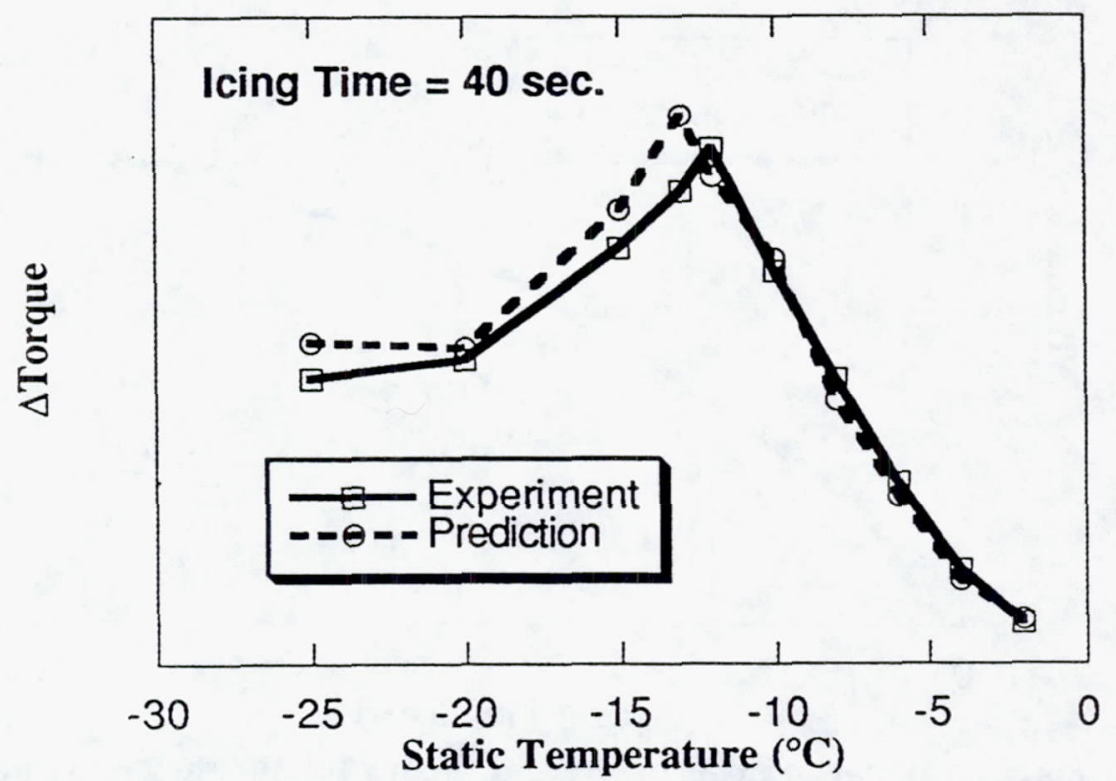

Figure 25. Comparison between experiment and theory for torque rise as a function of temperature for an icing time of $\mathbf{4 0}$ seconds (constant collective mode). 
Public reporting burden for this collection of information is estimated to average 1 hour per response, including the time for reviewing instructions, searching existing data sources, gathering and maintaining the data needed, and completing and reviewing the collection of information. Send comments regarding this burden estimate or any other aspect of this Services, Directorate for Information Davis Highway, Suite 1204, Arlington, VA 22202-4302, and to the Office of Management and Budget, Paperwork Reduction Project (0704-0188), Washington, DC 20503.

\begin{tabular}{|l|c|c|}
\hline 1. AGENCY USE ONLY (Leave blank) & $\begin{array}{r}\text { 2. REPORT DATE } \\
\text { January } 1994\end{array}$ & $\begin{array}{r}\text { 3. REPORT TYPE AND DATES COVERED } \\
\text { Technical Memorandum }\end{array}$ \\
\hline
\end{tabular}

\section{TITLE AND SUBTITLE}

An Overview of a Model Rotor Icing Test in the NASA Lewis

Icing Research Tunnel

\section{AUTHOR(S)}

Randall K. Britton, Thomas H. Bond, and Robert J. Flemming

\section{FUNDING NUMBERS}

WU-505-68-11

\section{PERFORMING ORGANIZATION NAME(S) AND ADDRESS(ES)}

National Aeronautics and Space Administration

Lewis Research Center

Cleveland, Ohio 44135-3191
8. PERFORMING ORGANIZATION REPORT NUMBER

E-8340
9. SPONSORING/MONITORING AGENCY NAME(S) AND ADDRESS(ES)

National Aeronautics and Space Administration

Washington, D.C. 20546-0001
10. SPONSORING/MONITORING AGENCY REPORT NUMBER

NASA TM-106471

AIAA-94-0716

\section{SUPPLEMENTARY NOTES}

Prepared for the 32nd Aerospace Sciences Meeting and Exhibit, sponsored by the American Institute of Aeronautics and Astronautics, Reno, Nevada, January 10-13, 1994. Randall K. Britton, Sverdrup Technology, Inc., Lewis Research Center Group, 2001 Aerospace Parkway, Brook Park, Ohio 44142 (work funded by NASA Contract NAS3-25266); Thomas H. Bond, NASA Lewis Research Center; Robert J. Flemming, Sikorsky Aircraft Division, UTC, Stratford, Connecticut. Responsible person, Randall K. Britton, organization code 2720, (216) 433-1064.

\begin{tabular}{l|l} 
12a. DISTRIBUTION/AVAILABILITY STATEMENT & 12b. DISTRIBUTION CODE
\end{tabular}

Unclassified - Unlimited

Subject Category 02

\section{ABSTRACT (Maximum 200 words)}

During two entries in late 1989, a heavily instrumented sub-scale model of a helocopter main rotor was tested in the NASA Lewis Research Center (LeRC) Icing Research Tunnel (IRT). The results of this series of tunnel tests have been published previously. After studying the results from the 1989 test and comparing them to predictions, it became clear that certain test conditions still needed investigation. Therefore, a re-entry of the Sikorsky Aircraft Powered Force Model (PFM) in the IRT was instituted in order to expand upon the current rotorcraft sub-scale model experimental database. The major areas of interest included expansion of the test matrix to include a larger number of points in the FAA AC 29-2 icing envelope, inclusion of a number of high power rotor performance points, close examination of warm temperature operations, operation of the model in constant lift mode, and testing for conditions for icing test points in the full scale helicopter database. The expanded database will allow further and more detailed examination and comparison with analytical models. Participants in the test were NASA LeRC, the U.S. Army Vehicle Propulsion Directorate based at LeRC, and Sikorsky Aircraft. The model rotor was exposed to a range of icing conditions (temperature, liquid water content, median droplet diameter) and was operated over ranges of shaft angle, rotor tip speed, advance ratio, and rotor lift. The data taken included blade strain gage and balance data, as well as still photography, video, ice profile tracings, and ice molds. A discussion of the details of the test is given herein. Also, a brief examination of a subset of the data taken is also given.

\section{SUBJECT TERMS}

Icing; Model rotor testing; Icing Research tunnel

\begin{tabular}{|c|c|}
\hline & $\begin{array}{l}\text { 15. NUMBER OF PAGES } \\
24\end{array}$ \\
\hline & $\begin{array}{r}\text { 16. PRICE CODE } \\
\mathrm{AO} 3\end{array}$ \\
\hline $\begin{array}{l}\text { 19. SECURITY CLASSIFICATION } \\
\text { OF ABSTRACT } \\
\text { Unclassified }\end{array}$ & 20. LIMITATION OF ABSTRACT \\
\hline
\end{tabular}

\begin{tabular}{c|c|c|}
\hline $\begin{array}{c}\text { 17. SECURITY CLASSIFICATION } \\
\text { OF REPORT } \\
\text { Unclassified }\end{array}$ & $\begin{array}{c}\text { 18. SECURITY CLASSIFICATION } \\
\text { OF THIS PAGE } \\
\text { Unclassified }\end{array}$ & $\begin{array}{c}\text { 19. SECURITY CLASSIFICATION } \\
\text { OF ABSTRACT } \\
\text { Unclassified }\end{array}$ \\
\hline
\end{tabular}

